\title{
İntramedüller Çivi Uygulaması Sonrası Kırık Kaynama Problemi Olan Tibia Kırığı Vakalarında Uygulanan Farklı Dinamizasyon Tekniklerinin Karşılaştırılması ${ }^{*}$
}

\author{
Ömer Kays ÜNAL, Mirza Zafer DAĞTAŞ \\ Maltepe Üniversitesi Tıp Fakültesi, Ortopedi ve Travmatoloji Anabilim Dalı, İstanbul.
}

\begin{abstract}
ÖZET
Çalışmamızda intramedüller çivi (IMMÇ) uygulanan tibia kırı̆ğı vakalarında dinamik kilitleme ve kaynama gecikmesi nedeniyle ikincil dinamizasyon uygulanan vakaları kaynama süreleri yönünden karșllaştırmak amaçlanmıștır. Mayıs 2002 ile Eylül 2019 tarihleri arasında tibia kırı̆ı nedeniyle İMÇ kullanılarak kapalı redüksiyon internal fiksasyon uygulanan 95 hasta çalışmaya alındı. Hastalar dinamizasyon tekniklerine göre 3 gruba ayrıldı. Birinci grup dinamik kilitleme yapılan hastalar, ikinci grup dinamizasyon amacıyla sadece statik vida çıkarılan hastalar, 3. grup dinamizasyon amacıyla dinamik ve statik tüm vidalar çıkarılan hastalardı. Gruplar; demografik bilgiler, sigara kullanımı, kırık tipi ve kaynama süresi açısından karşılaştırmalı olarak değerlendirildi. Çalışmaya dahil edilen 95 hastanın 61'i erkek, 34'ü kadındı. Hastaların yaş ortalaması 35 (19 - 63) idi. Hastaların ortalama takip süresi 21,3 (12 - 30) hafta idi. Grup 2'de kaynama süresinin diğer gruplara göre daha uzun olduğu görüldü. Tüm hastalar ve ayrı ayrı gruplar arasında yaş ve cinsiyet ile kırık kaynama süresi arasında anlamlı istatistiksel bir ilişsi saptanmamıștır ( $\mathrm{p}>0.05$ ). Tüm gruplar için sigara kullanan hastalarda kırık kaynama süresinin daha uzun olduğu saptanmıştır $(\mathrm{p}<0.05)$. Kırık tipine göre kırık kaynama süreleri arasında istatistiksel olarak anlamlı bir fark saptanmadı ( $\mathrm{p}>0.05)$. Gruplar, 12. haftadan tam kaynama gerçekleșene kadar geçen süreler açısından incelendiğinde grup 2'de istatistiksel olarak grup 3'ten daha uzun bir kaynama süresi olduğu saptandı $(\mathrm{p}<0.05)$. Çalışmamızın sonucunda; İMÇ uygulanan ve kaynama problemi olan vakalarda en etkili dinamizasyonun, kırık hattına uzak olan noktadan tüm vidaların çıkarılarak çivinin aksiyel yönde hareketine izin vererek sağlandığı görülmüşsür.
\end{abstract}

Anahtar Kelimeler: Tibia kırıkları; Kırık sabitlenmesi. İntramedüller; Kırıklar. Kaynamamış; Kırık iyileşmesi.

Comparison of Different Dynamization Techniques Applied in Cases of Tibial Fractures with Fracture Healing Problem after İntramedullary Nail Operation.

\begin{abstract}
Our aim is to compare dynamic locking and secondary dynamization technics which were applied for fracture healing problems after intramedullary nail (IMN) operation for tibia fracture. Ninety-five patients who were operated with IMN for tibia fracture between May 2002 September 2019 were included. Patients divided into three groups. Group 1 was dynamic locked, group 2 was static screws removed patients for dynamization and group 3 was all screws removed patients for dynamizations. Groups were compared according to demographics, smoking, fracture type and fracture union time. Sixty-one patients were male and 34 were female. Mean age of the patients was 35 (19-63). Mean follow-up was 21,3 (12 - 30) weeks. According to comparative analysis between group 1 and 2 and group 2 and 3 showed that fracture union time was longer in group 2 than others. There was no any statically significant relation between age, sex, fracture type and fracture union time ( $>0.05)$. For all groups, fracture union time was longer in smoking patients than other patients $(p<0.05)$. Analysis of groups according to interval between $12^{\text {th }}$ week and fracture union time showed that group 2 had longer fracture union time than group $3(\mathrm{p}<0.05)$. As a result of this study, removal of the all locking screws of IMN at the side far from fracture is most effective dynamization method for fracture healing problems after IMN operations.
\end{abstract}

Key Words: Tibial fractures; Fracture fixation. İntramedullary; Fractures. Ununited; Fracture healing.

Geliş Tarihi: 23.Eylül.2020

Kabul Tarihi:09.Kasım.2020

Dr. Ömer Kays ÜNAL

Maltepe Üniversitesi Tıp Fakültesi Hastanesi

Ortopedi ve Travmatoloji Anabilim Dalı

Bağlarbaşı mah. Feyzullah cad. Maltepe Üniversitesi

Tıp Fakültesi Hastanesi No:39

Maltepe - İstanbul

Tel: + +90(216) 4440626

E-posta: omerkays@gmail.com
Uluslararası 2. Türk Dünyası Ortopedi ve Travmatoloji Kongresi'nde (11-15 Eylül 2019, Almati - Kazakistan) sözlü bildiri olarak sunulmuştur.

Yazarların ORCID ID Bilgisi:

Ömer Kays ÜNAL: 0000-0002-9445-1552

Mirza Zafer DAĞTAŞ: 0000-0001-6861-6555 


\section{Ö.K. Ünal ve M.Z. Dağtaş}

Günümüzde, intramedüller çivileme (İMÇ) yöntemi uzun kemik kırıklarında artık standart bir tedavi yöntemi olmuştur. İMÇ uygulanan vakalarda rapor edilmiş olan kaynama oranı $\% 90$ seviyelerindedir ${ }^{1,2}$. Ancak bazı vakalarda kaynama sürecindeki gecikmeye bağlı olarak geç kaynama ve hatta kaynamama görülebilmektedir. Yetersiz tespit, kırık hattındaki kanlanma problemleri ve enfeksiyon, kaynama problemlerinin etiyolojisinde başlica sebeplerdir ${ }^{3}$. Dinamizasyon, çivi değişimi, kemik greftleri ile birlikte kompresyon plaklama, distraksiyon osteogenezisi ve vaskülarize fibula transferi bu tip vakalarda kaynamanın uyarılmaS1 ve hızlanması için kullanılan yöntemlerdir ${ }^{3,4}$. Son dönemde kaynama gecikmesi olan vakalarda trombositten zengin plazmanın da etkili olduğunu gösteren yayınlar mevcuttur ${ }^{5}$. Tanımlanan bu yöntemler içerisinde en basit ve düşük maliyetli olan yöntem dinamizasyondur. Dinamizasyon, kırık iyileşme sürecinde hızlanma sağlamak için sıklıkla başvurulan bir metottur. Genel tanım olarak dinamizasyon, çivi ile tübüler kemik arasında kemiğin aksiyel eksenine paralel şekilde minimal teleskopik hareket sağlanarak kırık hattında kemik dokuların birbirine temasının artması, kırık hattında kompresyon oluşması ve bu şekilde kırık kaynamasının uyarılması işlemidir ${ }^{6,7}$.

Dinamizasyon, dinamik kilitleme şeklinde ilk operasyonda kırık hattına uzak olan deliklerden sadece dinamik delik kilitlenerek veya ikincil dinamizasyon olarak proksimal ve distalden statik kilitlenen çivinin ikinci bir operasyon ile kırık hattına uzak olan noktasından statik vidaların çıkarılması seklinde ikiye ayrılmaktadır ${ }^{8}$. Dinamik kilitleme ile operasyon sonrası hızlı bir şekilde dinamizasyonun başladığı ve kaynama sürecinin hızlandığı ön görülmektedir. İkincil dinamizasyonda ise ilk operasyonda statik kilitlenen çivinin kaynama gecikmesi nedeniyle ikinci bir operasyon ile kırık hattına uzak olan taraftan statik vidaların çıkarılarak dinamizasyonun sağlanmasını amaçlanır ${ }^{8,9}$. Bu işlem genellikle IMÇ uygulandıktan 2-3 ay sonra kırık kaynamasında gecikme gözlendiğinde uygulanmakta$\mathrm{d}_{1} \mathrm{r}^{7,10,11}$. Dinamizasyon sonrası başarılı kaynama oranı ile ilgili birçok çalışma olup başarı oranları oldukça değişkenlik göstermekte ve \%19-\%82 olarak belirtilmektedir $^{6,12}$.

Dinamizasyon; kırık hattına en uzak statik vidaların çıkarılması olarak tanımlanırken aynı seansta dinamik vidanın çıkarılması ile ilgili net bir veri mevcut değildi. Dinamik kilitleme veya dinamizasyon amaciyla sadece statik vidaların çıkarıldığı dinamik vidanın bırakıldığı vakalar için, teorik olarak çivi üzerindeki dinamik delik içerisinden gönderilen vida rotasyonel stabiliteyi sağlarken aksiyel harekete izin verdiği kabul edilmektedir. Bazı merkezlerde dinamizasyon dinamik kilitleme olarak ilk operasyondan itibaren yapılırken kimi merkezlerde ikincil dinamizasyon olarak yapılmaktadir. Ancak dinamik kilitleme yapılan vakalar, dinamizasyon amacıyla kırık hattına uzak olan uçta sadece statik vidaların çıkarıldığ vakalar ve tüm vidaların çıkarıldığı vakalar arasında hangi yöntemin kırık kaynamasını hızlandırması açısından daha başarılı olduğuna dair net bir veri yoktur.

Bu çalışmada amacımız, İMÇ uygulanan tibia kırığı vakalarında dinamizasyon amacıyla ilk operasyonda dinamik kilitleme yapılan, ikincil dinamizasyon amacıyla sadece statik vidaların çıkarıldığı dinamik vidanın bırakıldığı vakalar ile ikincil dinamizasyon amacıyla statik ve dinamik vidaların beraber çıkarıldığı vakaları kırık kaynama süreleri açısından karşılaştırmaktır. Çalışmamızın hipotezleri; 1) Dinamik kilitleme uygulanan vakalarda dinamizasyon yeterli değildir, 2) Dinamizasyon amaciyla sadece statik kilitleme vidalarını çıkarmak, dinamik kilitleme vidasını bırakmak, istenen dinamizasyon için yeterli olmayıp kaynama suresini uzatabilmektedir, 3) Dinamizasyon amacıyla kırık hattına uzak olan uçtaki tüm vidaların çıkarılması kaynama açısından en iyi sonucu verir.

\section{Gereç ve Yöntem}

Dinamizasyon tekniklerinin karşılaştırması amaçlanan retrospektif kohort çalışmamızda Mayıs 2002 ile Eylül 2019 tarihleri arasında tibia kırı̆̆ı nedeniyle İMÇ kullanılarak kapalı redüksiyon internal fiksasyon uygulanan 256 hastasının verileri incelendi. Dahil olma ve hariç tutulma kriterlerine uyan 95 hasta çalışmaya alınd1. Dahil olma kriterleri; 18-65 yaş arası olmak, tibia kırığı nedeniyle İMÇ kullanılarak opere edilmiş olmak, dinamik kilitleme uygulanmış olmak, kaynamama veya geç kaynama nedeniyle ikincil dinamizasyon uygulanmış olmak idi. Hariç tutulma kriterleri; kırık kaynamasını etkileyecek sistemik hastalığı olmak, tibia kırı̆̆ının açık kırık olması, tibia diyafiz kırığı dışında aynı taraf fibula diyafiz kırığı hariç ek kırıkları olmak, operasyon bölgesinden kaynama gecikmesi veya kaynamama gibi patolojiler dışında herhangi bir sebepten dolayı yeniden operasyon geçirmiş olmak, kaynama gecikmesi veya kaynamama durumunda dinamizasyon dişındaki kırık kaynamasını hızlandıran yöntemlerin kullanılmış olması, enfeksiyon, derin ven trombozu gibi kırık bölgesini etkileyen komplikasyonlar geçirmiş olmak idi.

\section{Cerrahi Teknik ve Takip;}

Genel, spinal ya da epidural anestezi altında gerekli arıtım ve örtümü takiben diz $90^{\circ}$ fleksiyon pozisyonunda iken, patellar tendon orta hattından olacak şekilde patella alt uçtan başlayıp tuberositas tibia da sonlanacak şekilde, yaklaşı $5 \mathrm{~cm}$ 'lik bir insizyon uyguland. Cilt ve cilt altı geçildikten sonra patellar tendon'a ulaşıldı ve uzunlamasına ortadan ikiye ayırıldı. İMÇ'nin ilk giriş noktasını belirlemek için skopi eşliğinde koronal düzlemde tibial krestin 3 mm mediali ile sagital düzlemde tibia eklem yüzü ve tibia anterior metafiz birleşim noktasının kesişim noktası belir- 


\section{Dinamizasyon Sonuçlarının Karşılaştırması}

lendi. Awl yardımı ile diz hiperfleksiyonda posterior korteks korunarak çivi giriş yeri intramedüller yönelimli olacak şekilde hazırlandı. Skopi eşliğinde kırık hattında redüksiyon sağlanarak proksimal çivi giriş deliğinden gönderilen kılavuz teli medüller kanal boyunca gönderilerek kırık hattı geçildi. Kılavuz teli üzerinden en küçük oyucu ile başlanarak ve $0.5 \mathrm{~mm}$ arttırılarak ölçülen medulla çapına uygun olana kadar medulla oyma işlemi yapıldı. Oyma işleminden sonra uygun boy çivi, çivi tutucu yardımı ile proksimal delikten geçirilerek kılavuz teli boyunca gönderildi. Çivi yerleştirildikten sonra skopi yardımı ile çivi üst ucunun proksimal giriş deliğine tam yerleştiği, kırık hattında tam redüksiyonun sağlandığı, kırık hattında gap olmadığı ve distal uçta çivi alt ucu ile ayak bileği arasındaki mesafe kontrol edildi. Distal kilit vidaları medialden laterale veya anteriordan posteriora, tibia anatomik aksına dik pozisyonda, uygun kilit deliklerinden skopi eşliğinde serbest olarak yerleştirildi. Rotasyon ve redüksiyon kontrolü skopi eşliğinde yapıldıktan sonra kırık hattında gap olan vakalarda proksimalden retrograd çakma tekniği ile kırık hattına kompresyon uygulandı. Proksimal çivi giriş yerinde çivinin proksimal ucunun patellar tendonu irrite edecek şekilde çıkmadığ 1 lateral skopi görüntüsü ile teyit edildikten sonra proksimal kilitleme çiviye bağlı tutucu üzerinden yapıldı. Çivinin proksimal ve distalden kilitlenmesi, kırığın yeri ve stabilitesine bağlı olarak kırık hattına uzak olan noktada bazı hastalara dinamik kilitleme şeklinde uygulanırken bazı hastalara statik, bazı hastalara da statik ve dinamik kilitleme kombine şekilde uygulandı. Çivinin tepe vidası uygun boyda uygulandı. Son skopi kontrolü yapıldıktan sonra insizyonlar irrige edilerek cilt altı ve cilt anatomisine uygun olarak sütüre edildi, pansuman yapıldı ve operasyon sona erdirildi.

Operasyon sonrası poliklinik kontrollerinde kırık kaynama takipleri radyolojik görüntülemelere göre vakaların RUST (The Radiographic Union Scale in Tibial Fractures) skoru hesaplanarak yapıldı. RUST skorlama yöntemi kırık hattındaki tüm kortekslerdeki kallus dokusu ve kırık hattının görünürlüğü baz alınarak uygulanmaktadır. Kırığın radyoloji görüntüleri RUST skorlama yöntemi kullanılarak 4 (belirgin kaynama yok) - 12 (belirgin kaynama mevcut) arasında puanlanır (13) (Tablo I).

Tablo I. RUST değerlendirme kriterleri ve puanlama

\begin{tabular}{|ccc|}
\hline Her korteks için puan* & \multicolumn{2}{c|}{ Radyolojik kriterler } \\
\cline { 2 - 3 } & Kallus & Kırık hattı \\
\hline 1 & Yok & Belirgin \\
2 & Var & Belirgin \\
3 & Var & Belirgin değil \\
\hline
\end{tabular}

RUST: The Radiographic Union Scale in Tibial Fractures * Herbir korteks için (anterior, posterior, medial ve lateral) ayrı ayrı puanlama yapılır. Puanların toplamına göre RUST skoru 4 (belirgin kaynama yok) ve 12 (belirgin kaynama var) arasında belirlenir.
Tüm vakaların kırık kaynama süreci bu skorlama yöntemi kullanılarak yapıldı. Takiplerde çekilen grafilerin değerlendirilmesinde RUST skorlamasında 12 puan alan vakalar tam kaynamış olarak değerlendirildi ve kaynama süresi(hafta) ilk operasyon tarihi ile 12 puan verilen grafinin çekildiği tarih aralığı olarak değerlendirildi.

Ameliyat sonrasi 12. haftanın sonunda RUST skoru 12 'nin altında olan hastalar kaynama gecikmesi olarak değerlendirilerek dinamizasyon operasyonu planland. Dinamizasyon operasyonu planlanan hastalar genel, spinal ya da epidural anestezi altında gerekli arıtım ve örtümü takiben skopi eşliğinde kırık hattına uzak olan tarafta kilit vidası çıkarma işlemi uygulandı. İlk operasyonda statik veya dinamik kilitleme yapilan hastalarda vidalar tamamen çıkarılırken ilk operasyonda statik ve dinamik kombine kilitleme uygulanan hastalarda statik vidalar çıkarılıp dinamik vidalar bırakıldı (Şekil 1).
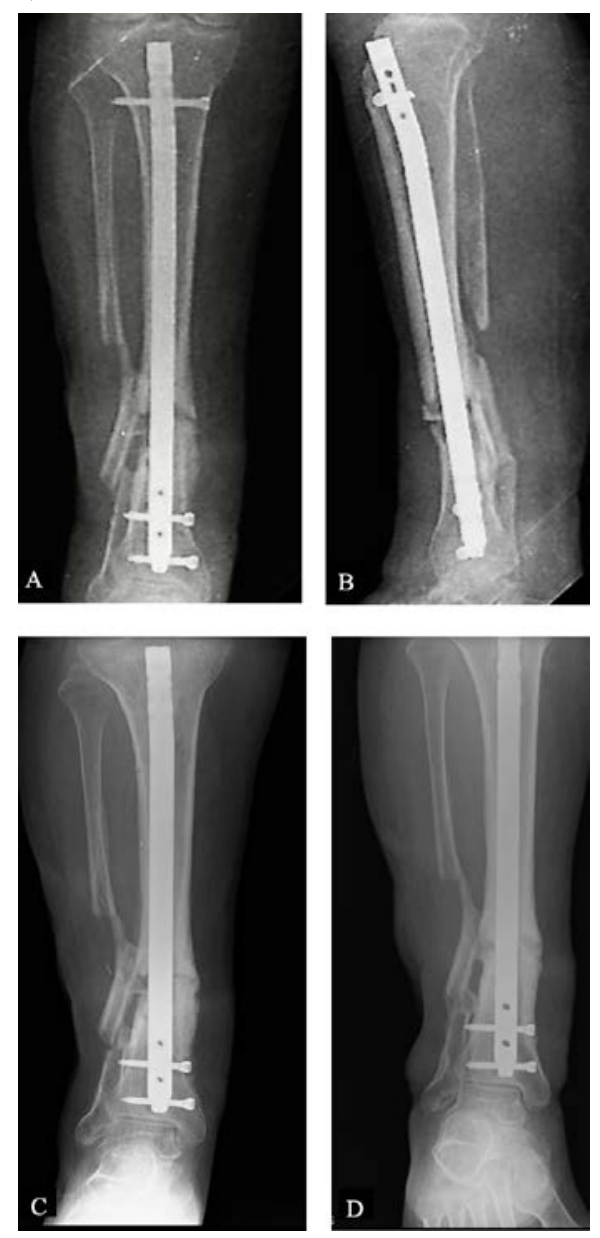

Şekil 1.

Ilk ameliyatta dinamik kilitleme uygulanan hastanın anteroposterior (A) ve lateral (B), 12. hafta ikincil

dinamizasyon sonrasi (C) ve 16. haftada tam kaynama sonrasi (D) grafileri.

Dahil edilme ve hariç tutulma kriterlerine uyan hastalar 3 gruba ayrıldı. 1. grup; ilk operasyonda dinamik kilitleme yapılan hastalar, 2. grup; ilk operasyondan 


\section{Ö.K. Ünal ve M.Z. Dağtaş}

sonra kaynama problemi olması nedeniyle ikinci bir operasyon ile statik vidaların çıkarılıp dinamik vidanın bırakıldığı vakalar, 3. grup; ilk operasyonda sadece statik kilitleme veya dinamik kilitleme yapılan ve takiplerde kaynama problemi olması nedeniyle ikinci bir operasyon ile tüm vidaların çıkarıldığ 1 vakalardı.

Gruplar; demografik bilgiler, sigara kullanımı ve kırık tipi ile kaynama süresi arasındaki ilişki açısından değerlendirildi. Ayrıca tüm gruplar ilk operasyon ile tam kaynamanın gerçekleştiği zaman arasında geçen süre açısından incelendi. Tüm gruplar 12. hafta RUST skorları açısından karşılaştırıldı. Grup 2 ve grup 3, 12 . hafta ile tam kaynama gerçekleştiği zaman arasındaki süre ve RUST skor farkı açısından da ayrıca karşılaştırild1.

\section{Etik kurul onayl:}

Çalışmamız Helsinki Bildirgesi prensiplerine uygun olarak planlanmış ve Maltepe Üniversitesi Klinik Araştırmalar Etik Kurulu tarafindan 08/05/2020 tarihinde onaylanmıştır. (Sayı:2020/900/22).

\section{Istatistiksel analiz:}

Verilerin analizi için SPSS 25.0 programı kullanıldı. Demografik veriler için frekans analizi uygulandı. Karşılaştırmalı analizlerde parametrik veriler karşılandığında ki-kare testi, student t-test ve ANOVA, karş1lanmadığında non-parametrik karşılıkları olan Mann Whitney-U testi ve Kruskall Wallis analiz yöntemi uygulandı. İstatistiksel anlamlılık düzeyi olarak $\mathrm{p}<0,05$ kabul edildi.

\section{Bulgular}

Çalışmaya dahil edilen 95 hastanın 61'i erkek, 34'ü kadındır. Hastaların yaş ortalaması 35 (19-63) dir. Hastalardan 61'i (13 kadın - 48 erkek) aktif sigara içicisidir. Hastaların ortalama takip süresi 21,3 (12 30) haftadır. Dinamizasyon tekniklerine göre yapılan gruplamada 29 hasta grup 1'de, 35 hasta grup 2'de, 31 hasta grup 3'de yer almaktadır. Hastaların gruplara göre demografik bilgileri ve ortalama kırık kaynama süreleri tablo olarak verilmiştir (Tablo II).

Tablo II. Çalışmaya dahil edilen hastaların demografik bilgiler

\begin{tabular}{|c|c|c|c|c|}
\hline \multirow{2}{*}{$\begin{array}{l}\text { Demografik } \\
\text { bilgiler }\end{array}$} & \multicolumn{4}{|c|}{ Gruplar } \\
\hline & Grup 1 & Grup 2 & Grup 3 & Toplam \\
\hline $\begin{array}{l}\text { Yaş ortalaması } \\
\text { (min. - maks.) }\end{array}$ & 35 (19-63) & $36(21-60)$ & $35,5(21-62)$ & $35(19-63)$ \\
\hline Cinsiyet (K/E) (n) & $16 / 26$ & $14 / 21$ & $4 / 14$ & $34 / 61$ \\
\hline $\begin{array}{l}\text { Sigara kullanımı } \\
(+/-)(\mathrm{n})\end{array}$ & $26 / 16$ & $22 / 13$ & $13 / 5$ & $61 / 34$ \\
\hline $\begin{array}{l}\text { Kırık kaynama } \\
\text { süresi (ort.) } \\
\text { (min.- maks.) }\end{array}$ & $13,6(6-22)$ & $19,6(15-25)$ & $16,1(14-19)$ & $17(6-25)$ \\
\hline
\end{tabular}

K: Kadın, E: Erkek, min.: minimum, maks.: maksimum, ort.: ortalama
AO/OTA (Arbeitsgemeinschaft für Osteosynthesefragen / Orthopaedic Trauma Association) siniflamasina göre 20 hasta 42-A1, 34 hasta 42-A2, 9 hasta 42-A3, 26 hasta 42-B1, 6 hasta 42-B2 grubunda yer almaktadir (Tablo III) $)^{14}$

Tablo III. Kırık tipinin gruplara göre dağılımı

\begin{tabular}{|lcccc|}
\hline AOIOTA & \multicolumn{4}{c|}{ Gruplar } \\
\cline { 2 - 5 } Siniflaması (n) & Grup 1 & Grup 2 & Grup 3 & Toplam \\
\hline $42-A 1$ & 8 & 9 & 3 & 20 \\
$42-A 2$ & 15 & 13 & 6 & 34 \\
$42-A 3$ & 4 & 4 & 1 & 9 \\
$42-B 1$ & 11 & 8 & 7 & 26 \\
42-B2 & 4 & 1 & 1 & 6 \\
\hline
\end{tabular}

AO/OTA: Arbeitsgemeinschaft für Osteosynthesefragen / Orthopaedic Trauma Association

Gruplar kırık kaynama süreleri açısından karşılaştırıldığında ortalama kırık kaynama süreleri grup 1 için 13,6 hafta (6-22 hafta), grup 2 için 19,6 hafta (15-25 hafta), grup 3 için 16,1 hafta (14-19 hafta) olarak saptand1. Grup 1 - grup 2 arasinda ve grup 2 - grup 3 arasında kaynama süreleri açısından anlamlı fark saptandı ve her iki analizde grup 2'de kaynama süresinin diğer gruplara göre daha uzun olduğu görüldü $(\mathrm{p}<0.05)$. Grup 1 ve 3 arasinda grup 1 lehine fark olmasına rağmen bu sonuç istatistiksel olarak anlamlı bir fark değildi ( $\mathrm{p}>0.05)$.

Kaynama süresi ile yaş ve cinsiyet ilişkisine bakıldığında 40 - 60 yaş grubunda kaynama süresinin en uzun olduğu ve her iki cinsiyet için ortalama kaynama süresinin 16,4 hafta olduğu saptanmıştır. Tüm hastalar ve ayrı ayrı gruplar arasında yaş ve cinsiyet ile kırık kaynama süresi arasında anlamlı istatistiksel bir ilişki saptanmamıştır $(p>0.05)$. Sigara kullanımı ile kırık kaynama süresi ilişkisi incelendiğinde, tüm gruplar için sigara kullanımının iki kat fazla olduğu ve buna paralel olarak sigara kullanan hastalarda kırık kaynama süresinin kullanmayan hastalara oranla \%35 daha uzun olduğu saptanmıştır $(\mathrm{p}<0.05)$ (Şekil 2). Kırık tipine göre kırık kaynama süreleri arasında istatistiksel olarak anlamlı bir fark saptanmadı $(\mathrm{p}>0.05)$.

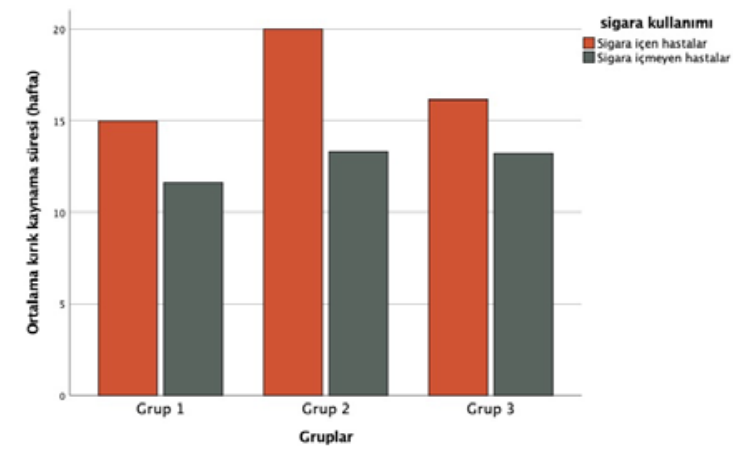

Şekil 2.

Gruplar arasındaki sigara kullanımı ve ortalama kırık kaynama süresi ilişkisi. 


\section{Dinamizasyon Sonuçlarının Karşılaştırması}

12. haftada ölçülen RUST skorları, 12. hafta ile tam kaynama gerçekleşene kadar geçen süre ve 12. haftada ve tam kaynama gerçekleştiği zaman ölçülen RUST skorları arasındaki fark tablo olarak verilmiştir (Tablo IV). Gruplar, 12. haftadan tam kaynama gerçekleşene kadar geçen süreler açısından incelendiğinde grup 2'de istatistiksel olarak grup 3'ten daha uzun bir kaynama süresi olduğu saptand $1(\mathrm{p}<0.05)$. Grup 2 ve grup 3 arasında 12. hafta RUST skor ile kaynamanın gerçekliği zamanki RUST skoru arasındaki fark değerlendirildiğinde, grup 3'te RUST skor farkının daha fazla olduğu görüldü. Ancak bu fark istatistiksel olarak anlamlı değildi ( $p>0.05)$.

Tablo IV. 12. hafta sonundaki kırık kaynama parametrelerinin gruplara göre dağılımı

\begin{tabular}{|lcccc|}
\hline $\begin{array}{l}\text { Kaynama parametreleri } \\
\text { (ort.) (min - maks.) }\end{array}$ & Grup 1 & Grup 2 & Grup 3 & Toplam \\
\cline { 2 - 5 } & $9,9(5-12)$ & $7,4(4-10)$ & $6(4-10)$ & $8,3(4-12)$ \\
$\begin{array}{l}\text { 12. hafta RUST skorları } \\
\begin{array}{l}\text { 12. hafta - tam kaynama } \\
\text { arasındaki süre }\end{array}\end{array}$ & $2,6(0-10)$ & $7,6(3-13)$ & $4.1(2-7)$ & $4,5(0-13)$ \\
$\begin{array}{l}\text { 12. hafta - tam kaynama } \\
\text { arası RUST skor farkı }\end{array}$ & $2(0-7)$ & $4,4(2-8)$ & $5,9(2-8)$ & $3,6(0-8)$ \\
\hline
\end{tabular}

RUST: The Radiographic Union Scale in Tibial Fractures(15), min.: minimum, maks.: maksimum, ort.: ortalama

\section{Tartışma ve Sonuç}

Literatürde dinamizasyonun uygulama şekli açısından birçok metot tanımlanmış olup birbirlerine olan üstünlükleri açısından net bir veri mevcut değildir. Genel olarak kırık hattına uzak olan noktadaki statik vidaların çıkarılması olarak tanımlanan dinamizasyon uygulamasını incelediğimiz çalışmamızda dinamik kilitleme, ikincil dinamizasyon amaciyla sadece statik vidaların çıkarılıp dinamik vidanın çıkarılmadığı ve tüm vidaların çıkarıldığı vakaların kaynama sürelerini ve bu sürelere etki eden faktörler açısından karşılaştırdık. Çalışma sonuçlarına göre ikincil dinamizasyon amacıyla kırık hattına uzak olan taraftan tüm vidaların çıkarılması kaynamanın uyarılması açısından en hızlı ve etkin yöntem olduğu saptandı. Ayrıca sigara kullanımının çivi dinamizasyon tekniğinden bağımsız olarak kırık kaynamasını negatif yönde etkilediği belirlendi.

Tibia kırıkları kaynama problemleri açısından diğer bölgelerin kırıklarına göre daha yatkın olup literatürde kapalı kırıklar için \%5-\%17, açık kırıklar için \%40'lara varan oranlarda bildirilmektedir ${ }^{15,16}$. Tibia kırığı sonrası geç kaynama veya kaynamama gibi durumlarda birçok tedavi yöntemi tanımlanmıştır. Dinamizasyon, greftleme, çivi değişimi, kompresyon plağı, eksternal fiksatör uygulama bu tür uygulamalardan en sık kullanılanlardır. Her vaka için tedavi algoritması değişebilse de bu yöntemler arasında dü- şük komplikasyon oranı, düşük maliyet ve yüksek başarı oranına sahip olan dinamizasyon sıklıkla uygulanan bir yöntemdir ${ }^{17}$.

Dinamizasyon, tanım olarak kırık hattında kırık uçlarının kemiğin aksiyel hattı boyunca hareketine izin vererek kaynamanın uyarılması olarak tanımlanmak$\operatorname{tad}^{18}{ }^{18}$. Dinamizasyon, en sik kırık hattına uzak olan noktadan statik vidaların çıkarılması şeklinde uygulanmaktadır. $\mathrm{Bu}$ uygulama sirasında dinamik vida çıkarılmamaktadır. Dinamik delikte bırakılan vida rotasyonel stabiliteyi sağlarken aksiyel harekete izin verir. Ancak dinamik vidanın dinamik delik içerisindeki konumu dinamizasyon miktarını etkilemektedir. Dinamik delikte kırık hattına yakın yerleştirilen vida kırık hattında kompresyona izin vermezken uzak yerleştirilen vidanın en fazla dinamizasyon etkisine sahip olduğu belirtilmektedir ${ }^{19,20}$. Bu konu ile ilgili literatürde yeterli kanıt bulunmamaktadır. Dinamizasyon, dinamik kilitleme şeklinde, ilk operasyonda kırık hattına uzak olan noktada sadece dinamik kilitleme deliğinden kilitlenerek de uygulanabilmektedir ${ }^{9}$. Farklı dinamizasyon tekniklerini karşılaştırdığımız çalışmamizda dinamizasyonun kaynama problemi olan olgularda kaynamayı hızlandırma konusunda pozitif etkiye sahip olduğunu ancak dinamik kilitleme ve statik vida çıkarılıp dinamik vida bırakılarak yapılan dinamizasyonun etkinliğinin düşük olduğunu gördük.

İkincil dinamizasyon ve dinamik kilitleme ile ilgili literatürde birçok çalışma olup farklı etkinlik oranları bildirilmektedir. Khalid ve ark. yaptıkları çalışmada, İMÇ uygulaması sırasında dinamik ve statik kilitleme yapılan femur diyafiz kırığı vakaları karşılaştırılmıştır. Operasyon sonrası kırık hattında $3 \mathrm{~mm}$ 'den fazla boşluk olan vakalarda dinamik kilitlemenin avantajlı olduğu ve statik kilitlenen vakalara göre daha hılı bir kırık kaynaması olduğu belirtilmiştir ${ }^{21}$. Doksan hastanın incelendiği bir diğer çalışmada, dinamik kilitleme uygulanan vakalarda 16 haftada \%100 kaynama oranı saptandığ 1 bildirilmektedir ${ }^{9}$. İkincil dinamizasyon ile ilgili Perumal ve ark. yaptıkları çalışmada ikincil dinamizasyon yapılan vakalarda kaynama oranı $\% 81,5$ olarak verilirken ortalama kaynama süresinin 6 ay olduğu belirtilmektedir ${ }^{22}$. Yaptığımız çalışmada, kaynama problemi olan vakalarda dinamizasyon uygulamalarımız sonucunda tüm hastalarda kaynama gözlenmiş ancak dinamizasyon tekniğine göre kaynama sürelerinde farklılıklar saptanmıştır. Ayrıca bu hastalarda kaynama süresi yaklaşık 4,5 ay sürdüğü gözlenmiştir.

Çalışmamızın sonuçlarına göre, dinamizasyon amacıyla statik vidaların çıkarıldığı ve dinamik vidanın bırakıldığı vakalarda kaynama süresi hem dinamik kilitleme uygulanan vakalardan hem de ikinci operasyon ile tüm vidaların çıkarıldığ 1 vakalardan daha uzun olmuştur. Dinamik kilitleme ve tüm vidalar çıkarılarak dinamizasyon uygulanan vakalar arasında kaynama süresi açısından dinamik kilitleme yapılan vakalar 
lehine fark saptanmıș olsa da istatistiksel olarak anlamlı bir fark olmadığı görülmüştür. İkincil dinamizasyon uygulanan gruplar kendi aralarında incelendiğinde, ikinci operasyon sonrası tüm vidaların çıkarıldığı grupta yine daha kısa sürede kaynamanın gerçekleştiği görülmektedir. Ayrıca 12. haftadaki kaynama miktarları değerlendirildiğinde tüm vidaların çıkarıldığı gruptaki kaynama miktarının daha az olduğu görüldü. Bu durum tüm vidaların çıkarılmasının kaynamanın hızlandırılması açısından en etkili yöntem olduğunu göstermektedir.

Pearson ve ark. yaptıkları meta-analiz sonucunda sigara kullanımının kaynama süresini 27,7 gün uzatt1ğ1 ve kaynamama riskini 2,2 kat arttırdığ1 saptanmış$\mathrm{tır}^{23}$. Çalışma sonuçlarımız literatür ile uyumlu olup, sigara kullanan hastalarda kaynama süresinin kullanmayanlara oranla üçte bir oranında daha uzun olduğu görülmüştür. Ayrıca Clark ve ark. yaptıkları ve yaş'a bağlı fizyolojik değişikliklerin kırık kaynaması üzerine etkilerinin incelendiği çalışmada yaş ile birlikte kırık kaynama sürecinin negatif etkilendiği belirtilmektedir ${ }^{24}$. Çalışmamızın sonuçlarına göre yaş ve cinsiyet ile kaynama süreleri arasında anlamlı bir ilişki saptanmamıştır.

Çalışmanın güçlü yanları, kırık kaynama kriterinin standardize edilmiş olması ve kaynamanın değerlendirilmesi açısından oluşabilecek sübjektif yorum fark1nın minimumda tutulmasıdır. Bir diğer özellik olarak dinamizasyon amacıyla statik vidaların çıkarıldı ğ ancak dinamik vidaların bırakıldığ tekniğinin ayrı bir grup olarak diğer dinamizasyon teknikleri ile karşılaştırılmış olmasıdır. Böylece literatürde kaynama sürecine olan etkisi net olarak değerlendirilmemiş olan dinamik vidanın bırakılması işleminin kaynama miktarına ve süresine olan etkisi karş1laştırmalı olarak incelenmiştir.

Çalışmanın en önemli kısıtlılığı 3 gruba da ikincil dinamizasyonun yapılmamış olması ve bu nedenden ötürü her üç grup için şartların eşit olmamasıdır. Bir diğer kısıtlılık da dinamizasyon operasyonlarının en önemli komplikasyonu olan ameliyat sonrası kısalık ile ilgili hasta kayıtlarında yeterli veri olmaması nedeniyle bu açıdan hastaların değerlendirilememiş olmasidir.

Çalışmamızın sonucunda; kırık tespiti için İMÇ uygulanan ve kaynama problemi olan vakalarda en etkili dinamizasyon metodunun, kırık hattına uzak olan noktadan statik ve dinamik tüm vidaların çıkarılarak çivinin aksiyel yönde hareketine izin vermek olduğu görülmüştür. $\mathrm{Bu}$ sonucun desteklenmesi için daha büyük örneklemler üzerinde yürütülecek randomize kontrollü çalışmalara ihtiyaç vardır.

\section{Teşekkür}

Yazarlar arasında herhangi bir çıkar çatışması yoktur. $\mathrm{Bu}$ çalışma herhangi bir kurum veya kuruluş tarafından desteklenmemiş veya bağışta bulunulmamıştır. Maltepe Üniversitesi Tıp Fakültesi Ortopedi ve Travmatoloji Anabilim Dalı ögrretim üyesi Prof. Dr. Ender Uğutmen'e çalışmanın analizinde ve yorumlanmasında verdiği destek için teşekkür ederiz.

\section{Etik Kurul Onay Bilgisi:}

Onaylayan Kurul: Maltepe Üniversitesi Klinik Araştırmalar Etik Kurulu

Onay Tarihi: $08 / 05 / 2020$

Karar No: 2020/900/22

\section{Kaynaklar}

1. Winquist RA, Hansen ST, Clawson DK. Closed intramedullary nailing of femoral fractures. A report of five hundred and twenty cases. J Bone Joint Surg Am. 2001;83(12):1912.

2. Wolinsky PR, McCarty E, Shyr Y, Johnson K. Reamed intramedullary nailing of the femur: 551 cases. J Trauma. 1999;46(3):392-9.

3. Gelalis ID, Politis AN, Arnaoutoglou CM, Korompilias AV, Pakos EE, Vekris MD, et al. Diagnostic and treatment modalities in nonunions of the femoral shaft. A review. Injury. 2012.43(7):980-8.

4. Lai D, Chen CM, Chiu FY, Chang MC, Chen TH. Reconstruction of juxta-articular huge defects of distal femur with vascularized fibular bone graft and Ilizarov's distraction osteogenesis. J Trauma. 2007;62(1):166-73.

5. Aksekili Mae, Ișık Ç, Çay N, Gürsoy S, Şimşek Me, Bozkurt M. Uzun Kemiklerin Diafiziel Kırıklarının Gecikmiş Kaynamasında Platelet-Rich Plasma Uygulanmasının Etkileri. Bozok Tıp Dergisi. 2016;6(1):1-6.

6. Wu CC, Shih CH. Effect of dynamization of a static interlocking nail on fracture healing. Canadian journal of surgery Journal canadien de chirurgie Can J Surg. 1993;36(4):302-6.

7. Kempf I, Grosse A, Beck G. Closed locked intramedullary nailing. Its application to comminuted fractures of the femur. J Bone Joint Surg Am. 1985 Jun;67(5):709-20.

8. Sankara rao P, Kiran kumar P, Choppara S, Deshpande S, Shankara rao Mch Orthopaedics Professor DM. Dynamızatıon For Delayed \& Non-Union Fractures Of Femur Shaft. Int. j. orthop. traumatol. surg. sci. 2017;3(2)614-616

9. Badami RN, Purohit S, Resident S. Dynamically locked intramedullary interlocking nail for fracture shaft of tibia: An effective surgical protocol with minimal complications. Indian J Orthop. 2018;4(1):41-43

10. Klemm K, Schellmann WD. Dynamic and static locking of the intramedullary nail. Monatsschr Unfallheilkd Versicher Versorg Verkehrsmed. 1972 Dec;75(12):568-75.

11. Brumback RJ. The rationales of interlocking nailing of the femur, tibia, and humerus: An overview. Clin Orthop Relat Res. 1996 Mar;(324):292-320.

12. Dagrenat D, Moncade N, Cordey J, Rahn BA, Kempf I, Perren SM. Effects of the dynamization of static bolt nailing. In vivo experimentation. Rev Chir Orthop Reparatrice Appar Mot. 1988;74 Suppl 2:100-4.

13. Kooistra BW, Dijkman BG, Busse JW, Sprague S, Schemitsch $\mathrm{EH}$, Bhandari $\mathrm{M}$. The radiographic union scale in tibial fractu- 


\section{Dinamizasyon Sonuçlarının Karşılaştırması}

res: Reliability and validity. J Orthop Trauma. 2010 Mar;24 Suppl 1:S81-6.

14. Müller ME, Koch P, Nazarian S, Schatzker J. The Classification of Diaphyseal Fractures. In: Müller EM (eds.) The Comprehensive Classification of Fractures of Long Bones. Berlin Heidelberg: Springer; 1990. 12-13

15. Hak DJ. Management of aseptic tibial nonunion. J Am Acad Orthop Surg. 2011 Sep;19(9):563-73.

16. Litrenta J, Tornetta P, Vallier H, Firoozabadi R, Leighton R, Egol K, et al. Dynamizations and Exchanges: Success Rates and Indications. J Orthop Trauma. 2015 Dec;29(12):569-73.

17. Vaughn J, Gotha H, Cohen E, Fantry AJ, Feller RJ, van Meter J, et al. Nail dynamization for delayed union and nonunion in femur and tibia fractures. Orthopedics. 2016 Nov 1;39(6):11171123.

18. Omerovic D, Lazovic F, Hadzimehmedagic A. Static or dynamic intramedullary nailing of femur and tibia. Med Arch. 2015 Apr;69(2):110-3.

19. Wu CC, Shih CH. A small effect of weight bearing in promoting fracture healing. Arch Orthop Trauma Surg. 1992;112(1):28-32.
20. Taglang G. The Operative Technique for the Latest Generation Gamma Nail (the Gamma3). In: Leung KS. et al. (eds) Practice of Intramedullary Locked Nails. Berlin, Heidelberg: Springer; 2006 133-137

21. Khalid M, Hashmi I, Rafi S, Shah MI. Dynamization Versus Static Antegrade Intramedullary Interlocking Nail In Femoral Shaft Fractures. J. Surg. Pak. Int. 2015; 20 (3): 76-81

22. Perumal R, Shankar V, Basha R, Jayaramaraju D, Rajasekaran S. Is nail dynamization beneficial after twelve weeks - An analysis of 37 cases. J Clin Orthop Trauma. 2018 OctDec;9(4):322-326.

23. Pearson RG, Clement RGE, Edwards KL, Scammell BE. Do smokers have greater risk of delayed and non-union after fracture, osteotomy and arthrodesis? A systematic review with meta-analysis. BMJ Open. 2016 Nov 14;6(11):1-10.

24. Clark D, Nakamura M, Miclau T, Marcucio R. Effects of Aging on Fracture Healing. Curr Osteoporos Rep. 2017 Dec; 15(6): 601-608. 
